\title{
Evaluation of the Knowledge about the Basic Food Processes and the Business Satisfaction of Workers in Some Food Plants in Mus Province, Turkey
}

\author{
Husnu Kasar \\ Mus Alparslan University, Vocational School of Social Sciences, \\ Hotel, Restaurant and Catering Services Department, Culinary Arts Program, Mus, Turkey \\ E-mail: husnu_kasar@hotmail.com \\ Suleyman Gokmen \\ Karamanoglu Mehmetbey University, Vocational School of Technical Sciences, \\ Department of Food Processing, Karaman, Turkey \\ E-mail: sugokmen42@ hotmail.com
}

\begin{abstract}
This research was carried out to determine the job satisfaction/dissatisfaction of the employees in food businesses operating in Mus province and the available food processing process information. In order to achieve this goal, the evaluation form determined by us within the framework of the rules by which job satisfaction can be determined was used. Obtained was evaluated statistically. In addition, job satisfaction questionnaires of participants who could not answer at least 2 of the questions about food processing correctly were not taken into consideration. According to the data obtained, it was determined that $28 \%$ of the participants whose questionnaire was not evaluated, $34 \%$ of those who declared that they collaborated with different departments in the business, $25 \%$ of those who see the business as their family, $40 \%$ of those who want orientation training in the business, those who say I would choose this if I had only one job $21 \%$ and $31 \%$ of those who declared that they do my job with pleasure. According to these results, it was concluded that training on basic food processes is necessary for the province of Mus province and that enterprises have important duties regarding the job satisfaction of employees.
\end{abstract}

Keywords: Mus Province, food processes, job satisfaction

DOI: $10.7176 /$ JSTR/6-13-03

\section{Muş İlinde Faaliyet Gösteren Bazı Gıda İşletmelerinde Çalışanların Temel Gıda Prosesleri İle İlgili Bilgi Birikimlerinin ve İș Tatminlerinin Değerlendirilmesi}

Özet

$\mathrm{Bu}$ araştırma, Muş ilinde faaliyet gösteren gıda işletmelerinde çalışanların iş tatmini/tatminsizliği ve mevcut gida işleme proses bilgilerinin belirlenmesi amacıyla yapılmıştır. $\mathrm{Bu}$ amaca ulaşmak için iş̧ tatmininin belirlenebildiği kurallar çerçevesinde tarafımızca belirlenen değerlendirme formundan yararlanılmıştır. Elde edilen istatistiksel olarak değerlendirilmiştir. Ayrıca gıda prosesleriyle ilgili sorulardan en az 2 sine doğru cevap veremeyen katılımcıların iş tatmin anket formları dikkate alınmamıştır. Elde edilen verilere göre anketi değerlendirilmeyenler katılımcıların \%28'i, işletmede farklı departmanlarla iş birliği yaptığını beyan edenler \%34'i, işletmeyi ailesi gibi görenler \%25'i, işletmede oryantasyon eğitiminin verilmesini isteyenler \%40'i, tek işim olsa bunu seçerim diyenler \%21'i ve işimi zevkle yaptığını beyan edenler \%31'i olduğu tespit edilmiştir. Bu sonuçlara göre Muş ilinde temel gıda prosesleriyle ilgili eğitimlerin verilmesinin gerekli olduğu ve çalışanların iş tatminiyle ilgili işletmelere önemli görevler düştüğünün sonucuna varılmıştır.

Anahtar Kelimeler: Muş İli, gıda prosesleri, iş tatmini

16 | $\mathrm{P}$ a g e

www.iiste.org 


\section{Giriș}

Yiyecek ve içecek, konaklama gibi hizmetlerin var olan kaynaklar ile en iyi şekilde kullanılmasıyla birlikte gida işletmelerinde en önemli faktörlerden maliyet, zaman, müşteri memnuniyeti vb. faktörler işletmeler açısından en önemli amaçlar arasındadır. İşletmelerin günümüzde ki şartlarında ayakta kalması, rakiplerine sunulan hizmetlerde avantaj sağlaması hızlıca gelişmekte olan teknolojinin takip edilmesi ve kullanımında hizmet kalitesinin belirli standartlarda olması gerekmektedir. Bunların yanı sıra işi gerçekleştiren, hizmetin oluşmasında ana karakter olan personellerin iş tatmininin sağlanması da önemli bir faktördür. Bu sebeple gıda işletmeleri dâhil diğer işletmelerde de personelin davranışına, kendini gerçekleştirmesine, çalışmasına, işe aidiyet duygusu beslemesine vb. elde edilen tatmin duygusu önem arz etmektedir (Giritlioğlu et al. 2016)

Personellerin işletmelerde tatmin duygusunu olumlu şekilde hissetmeleri, personellerin çalışmakta olduğu işletmenin bir parçası olduğunun düşüncesi, işletmeye aidiyet hissetmesi, çalışma zamanında daha verimli geçirmesi gibi olumlu etkiler yapmaktadır. Bunun yanı sıra olumlu tatmin duygusu personelin yaptıkları işlerde streslerin azalmasına, işlerin gerçekleştirilmesi noktasında kendine güvenme vb. birçok yönde katkı sağlamakla birlikte görevli ve sorumlu olduğun işin kalitesini de artırmaktadır (Çarıkcı, 2000). Gıda işletmelerinde yönetici pozisyonunda görev yapmakta olan kişilerin işletmede görev yapmakta olan çalışanın iş tatmin faktörlerini belirleyerek, işletmenin belirlenen hedeflere bu faktörler doğrultusunda yön vermeleri, işletmelerde meydana gelen veya gelebilecek sorunların önüne geçilmesi ve daha verimli, huzurlu bir çalışma ortamının oluşturulmasında yardımcı olacaktır (Kaya, 2007).

İşletmelerde yöneticilerin, personellerin iş tatmininin gerçekleştirilmesinden daha önce personellerin iş tatmininin yeterli ve doğru ölçebilecek bu kapsamda geçerli ve güvenilir ölçeklerin oluşturulması yöneticilerin sorumluluğundadır. Tatmin kelimesi; istenilen bir şeyin gerçekleşmesini, manevi olarak doygunluğa ulaşma anlamı taşımaktadır. İș tatminin ölçülmesinde ise kişinin öz değerlendirme yapması sonucu veya işin farklı yönlerinin toplanması sonucu ortaya çıkan durumlar iş tatmini/tatminsizliğine ulaşmada önemlidir.

İş tatminini etkileyen faktörler 2'ye ayrılmaktadır. Bunlar bireysel ve örgütsel faktörler olarak bilinmektedir.

\begin{tabular}{|l|l|}
\hline Bireysel Faktörler & Örgütsel Faktörler \\
\hline Yaş & Ücret ve sosyal haklar \\
\hline Cinsiyet & İşin niteliği \\
\hline Eğitim & Terfi (Yükselme olanakları) \\
\hline Hizmet süresi & Çalışma koşul ve şartları \\
\hline Medeni durum & Çalışma arkadaşları \\
\hline Kişilik & Yöneticiler ve Yönetim tarzı \\
\hline Kıdem (İş tecrübesi) & İş güvencesi \\
\hline Çocuk sahibi olma & Ortak kullanım alanları \\
\hline & Çalışma ortamları, iş kazaları ve sağlık riski \\
\hline & İş yükü \\
\hline & Kaynak yetersizliği \\
\hline
\end{tabular}


Yaş- iş tatmini arasındaki ilişkide kültür, çalışanın iş tecrübesi gibi kavramalar etkili olabilmektedir. Ayrıca bireylerin bilgi düzeyleri ve gereksinimler etkili olabilmektedir.

İș dünyasında geçmiş dönemde beri süregelen erkeklerin çalışması anlayışı son dönemlerde kadınlarında iş hayatına girmesi ile değişmeye başlamıştır. Her iki cinsiyetinde işletmeden farklı beklentileri bulunmaktadır. Erkekler her dönemde başarıya yönelik bir çalışma anlayışı bulunur iken kadınların işe yönelik bir iş tatmini bulunmaktadır. Kadınların çalışma hayatındaki beklentilerin daha düşük olması, evlerine erkeklere nazaran bakma yükümlülüklerinin daha az olması iş tatmini noktasında yüksek iş tatmini ile çalışmasında önemlidir (Özcan, 2010).

Çalş̧anların genel beklentisi eğitin düzeyi artıkça iç güdüsel olarak tatminin de artmasıdır. Kişinin beklentisinde iş tatmini ile-eğitim arasında paralel bir ilişki bulunmaktadır.

Çalışanların hizmet süresi ile yaș doğru orantılıdır. Uzun dönemler aynı işletmelerde çalışan kișiler de iş tatmini beklentisi artmaktadır. Kişilerin uzun süre girdikleri işyerinde çalışmaması, yer değiştirmesi iş tatminsizliğinin göstergeleri arasındadır (Pınar et al. 2008).

Kişilerin medeni durumları iş yaşamlarını da etkilemektedir. Evli çalışanlar diğer çalışanlara göre aile olarak sorumluluklarının da bulunması sebebiyle maddi olarak verilecek ödüller onlar açısından daha önemlidir. Evli kişilerin ailelerine bakma zorunluklarının yanı sıra çocuklarına da bakma zorunlulukları kişilerin çalışma ihtiyaçlarını artırmaktadır. İşletme açısından da evli düzenli bir hayatı olan personel tercih edilirliği artırabilmektedir (Karaçar, 2019)

Kişilik, birey tarafindan belirgin ve değişmeyen özelliklerin bütünü olarak düşünüldüğünde iş tatminin sağlanmasında önemli bir etkendir. Kişilerin kendilerinde var olan kişilik özellikleri bazı zaman olumlu etki gösterip yüksek iş tatmini içerirken, bazı zamanlarda ise olumsuz etki gösterip düşük iş tatminine sebep olabilmektedir.

Kıdem ile iş tatmini arasında güçlü bir bağ bulunmaktadır. Çalışanın statüsünün yüksek olması iş doyumunun da yüksek olduğunun göstergesi iken daha alt kademedeki işe bakması olumsuz sonuçlanmaktadır. İş tecrübesi kişinin özgeçmişine de yazması ile işletmelerde daha iyi konumlarda olması için kullanılabilir (Ayan, 2008).

Küçük yaşlarda bebeği olan kadınların daha düşük iş tatmin düzeyi bulunmaktadır. Erkeklerde ise bebek sahibi olmanın iş tatmin düzeyine olumsuz etkileri bulunmaktadır. Çocuk sayısı da iş tatminini etkileyen önemli bir faktördür.

İş tatminini etkileyen örgütsel faktörler aşağıda verilmiştir.

Ücret, personelin işletmede yaptığı katkılar sonucu hak ettiği değer olarak tanımlanabilir. Kişiler üzerinde iş tatminini olumlu veya olumsuz etkileyen en önemli faktörlerden biriside alınan maaştır. Çünkü kişi çalışma ortamında aynı seviye ve statüdeki başka personelin kendisinden daha fazla maaş aldığını bilmesi kişinin iş yerine karşı bakış açısını değiş̧irecek ve iş tatmini noktasında olumsuz verimde çalışmasına sebep olacaktır (Kösem, 2015).

Kişinin yaptığı işin zevkli ve eğlenceli olması, işletme içerisinde ve dışarıda değerli görülmesi, yapılacak işte belli tecrübe ve devamında bilgi gerektirmesi, işin gelişme boyutunda sürekli yeniliklere açık ve çalışanında kendini geliştirebileceği firsatların olması tatmin nedeni olarak sayılmaktadır (Pınar et al. 2008).

Terfi, personelin çalışmakta olduğu işletmede daha fazla ücret alması, kadro olarak üst kadroya geçmesi, yetki ve sorumlulukların artan bir statüye geçmesi veya atanmasıdır (Ayan, 2008).

İşletmenin çalışma koşulları ve şartları denilince o yerin güvenlik, konfor, ulaşım vb. faktörleri içerisine alan durumlardır (Pınar et al. 2008)

Çalışma ortamı personelin gün içindeki zamanını en fazla geçirdikleri yerlerden birisidir. Böyle bir durumda iş arkadaşları da kişi için oldukça önemlidir. Çalıma ortamında ben değil biz olgusu oluşturan işletmeler daha başarılı olacaktır.

İş ortamında yönetim ve yönetici tarzı çalışanın iş tatmininde oldukça önemli bir durumdur. Yöneticilerin sert veya yumuşak şekilde çalışana davranması iş tatminini etkileyebilmektedir (Dinler, 2019).

İşletme tarafından sağlanan iş güvencesi çalışanın kendini güvende hissetmesine ve işletmeye sahip çıkmasına böylelikle iş tatminin de artmasına sebep olabilmektedir. 


\section{İs Tatmininin / Tatminsizliğinin Sonuçları}
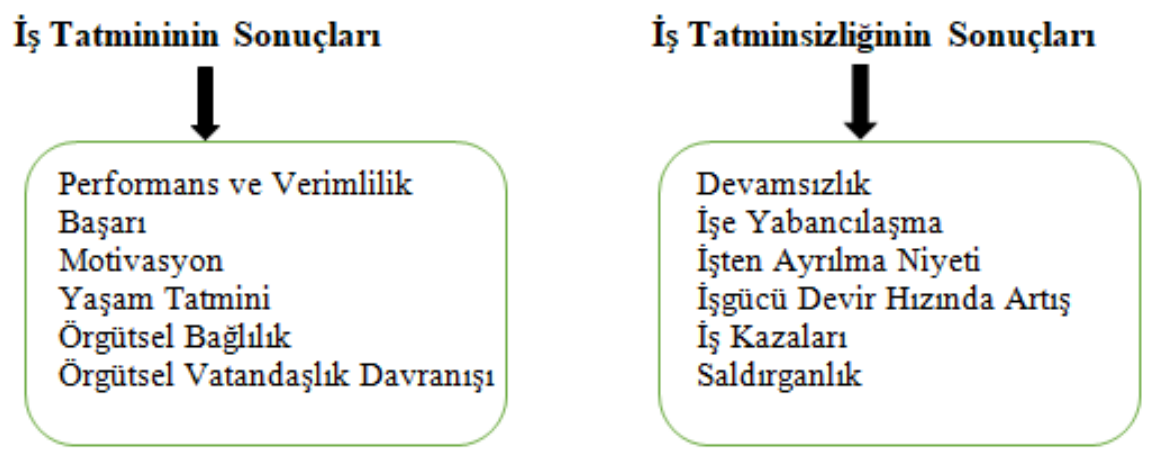

İş tatmininin sonuçları;

Performans iş tatminin de içsel ve dışsal olmak üzere iki farklı şekilde değerlendirilmektedir. İçsel ödül olarak kişinin yaptıkları işten başarma hissi duygusunun hissetmesini sağlanmasıdır. Dışsal ödül olarak alınan maaşa yapılan artış örnek gösterilebilmektedir.

Başarı insan iç yapısında bulunan ve işletmeleerde ki her personelin ulaşmak istedigi bir durumdur. Kişilerin başarıya ulaşma yolunda kendilerine bir hedef koyması ve bu hedeflere ulaşmada yapılan fedakarlık ve gayretler kişiyi başarıya götürecektir.

Kişinin ilerlemesini saglayan, yapılan işin daha başarılı olması için teşvik saglayan ihtiyaçlardır. Çalışanın motivasyonunun saglanması işletme içinde önemlidir. Motivasyonu saglanmış bir çalışan kişinin daha iyi çalışması, kişinin amaçlarına ulaşması için dikkatli davranması gibi etkenlere daha dikkat edecektir.

Örgütsel bağl1lık özellikle 20. yy sonunda önem kazanan bir konu olmuştur. Personelin çalışmakta oldugu işletme ile kendisini bütünleştirmesi, işletmeye aidiyet duygusu saglanması örgütsel bağl1lıgın en önemli göstergelerindendir. İşletmeye duyulan bağl1lık hissi artan personel kendisine gerekli oldugunu düşündügünde yöneticiler kendisinde sorumluluk vermeden kendisi isteyecek ve işletmenin kalite ve standartlarının her zaman üstte tutulmasını saglıyacaktır.

Çalışanların işletmede belirli olan görev ve sorumluluklarının dışında gercekleşen herhangi bir karşılık beklemeksizin istege baglı yapılan işle örgütsel vatandaşlık davranışı olarak bilinmektedir. İş tatminine ulaşmış kişi herhangi bir menfaat, cıkar beklemeden işletmenin yararı için gereken davranışı sergileyecektir (Ergüney, 2006).

İş Tatminsizliğinin Sonuçları ise;

İş tatmini düşük ise çalışanın devamsızlık günleri daha fazla olacaktır. Devamsızlık işi olumsuz etkileyen kaza, hastalık, sorumsuzluk gibi daha birçok sebeple işten ayrı kalınması olarak bilinmektedir (Pınar et al. 2008 ; Ayan, 2008).

Çalışanın işletmeden soğuması, işletmeye karşı bağlılık duyguların azalması sonucu oluşan bir durumdur. İșten yabancılaşma yöneticilerin fazla sorumluk vermesi, kişiye fazla iș yükü, çalışanın dile getirdiği şikâyetlerin giderilmemesi, yönetimin kendi düşüncesini yaptırma isteği gibi faktörler yabancılaşmaya neden olabilmektedir. İşe yabancılaşma yaşayan kişiler düşük iş verimliliğinde çalışan, işten soğuyan her firsatta işten uzaklaşma isteği bulunan kişiler olarak da bilinmektedir (Urhan, 2014). Kişinin işten ayrılma niyeti artık kişi için son nokta olarak düşünülebilir. İşletme kaybettiği personelin yerine aldığı personeli eğitimine ayırdığı maliyet, zaman, ortaya çıkabilecek müşteri memnuniyetsizliğ $i$ gibi sorunlar ile karşı karşıya kalabilecektir. Bu sebeple işletme çalışanın iş tatmini noktasında gerekli tedbir ve istekleri sağlamalıdır (Dinler, 2019 ).

İş kazaları işletmenin araç ve gereçleri yeterli olmaması, eski olması, çalışma ortamının (ses, gürültü, aydınlatma) yeterince uygun olmaması, dalgınlık, dikkatsizlik, stres gibi daha birçok sebep sonucu oluşabilmektedir. İş tatmini düşük olan personel işletmeden beklediği maddi-manevi eylemleri 
alamaması sebebiyle kendisini işe adapte edememesi sonucu iş kazaları meydana gelebilmektedir. Saldırganlık canlı veya cansız herhangi bir varlığa zarar vermeyi amaçlayan amaçlar bütünü olarak tanımlanmaktadır. İnsanlar işletmede yaşanan stres, öfke, hayal kırıklığı vb. bir çok zamanlarda karşısına çıkabilecek her türlü canlı ve cansız rollere zarar verme eğilimindedir.

İş tatminini ölçme yöntemleri aşağıda verilmiştir.

Puanlama ölçekleri ile iş tatmini ölçümü ve Anket ve mülakat yoluyla iş tatmini ölçümü olmak üzere ikiye ayrılmaktadır.

\begin{tabular}{|l|l|}
\hline Puanlama Ölçekleri ile Ölçüm & Anket ve Mülakat ile Ölçüm \\
\hline Minnesota Tatmin Ölçeği & Posta Yoluyla Uygulama \\
\hline Kritik Olaylar Yaklaşımı & Yüz yüze Uygulama \\
\hline İş Tanımlayıcı İndeks Yöntemi & Toplu Halde Uygulama \\
\hline
\end{tabular}

İş tatminin ölçülmesi için en fazla kullanılan ölçüm puanlama ölçekleri ile ölçümdür. Puanlama ölçeğinin dikkat çeken 2 adet yararı bulunmaktadır. Bunlar toplanan bilgilerin homojen olması bir diğeri ise değerlerin sayısal olarak ifade edilebiliyor olmasıdır.

Minnesota Tatmin Ölçeği 1967 yılında ortaya çıkmıştır. 1985 yılında Aslı Baycan tarafından Türkçeye çevrilmiştir. Likert Ölçeği Tekniği ile kişilere sorulan sorulara "hiç memnun değilim”, "memnun değilim", "kararsızım", "memnunum" ve "çok memnunum" gibi cevaplar ile kişinin iş tatmin ve tatminsizlik düzeyi ölçülmektedir. Sorulan sorulara verilen cevaplar ayrı ayrı incelenerek her madde için farklı sonuçlara ulaşılmaktadır.

Kritik olaylar yaklaşımı Herzberg tarafından geliştirilmiş bir uygulamadır. Kişilere iş çalışma ortamında kendilerini mutlu ve mutsuz hissettikleri anlar sorularak verilen cevaolar incelenerek iş tatmini/tatminsizliği boyutu ölçülmek istenmektedir. Kritik olaylar yaklaşımı uygulanma aşamasında kişi kendisini rahat hissetmeleri, düşünceleri rahatlıkla dile getirebilmelidir. Minnesota ölçeğinde bulunan herhangi bir sınırlama veya bir kalıbın içerisinde sorulara cevap verilmemektedir. Kritik olaylar yaklaşımı kişinin hissettiklerini anlatacağı sebebiyle zaman olarak dezavantajlı bir yöntemdir (Tor \& Esengün 2011).

İş tanımlayıcı indeks yöntemi, İş Tanımlayıcı indeksi ölçümünde beş faktör kullanılmaktadır. $\mathrm{Bu}$ faktörler; İşin kendisi, Yönetim kalitesi, Çalışma arkadaşlarıyla ilişkiler, Terfi imkanları, Ücret olmak üzere beş faktör içermektedir. Kişilerin verdikleri cevaplar yönetime hangi konularda eksiklikler olduğunu gösterecektir. 9,18,72 li ifadeyi içerebilen şekillerde hazırlanabilmektedir.

Anket ve mülakat ile ölçümde anket uygulaması iş tatmini/tatminsizliği ölçümünde uygulanan çalışanların kendileri tarafindan okunup, cevaplandırıldığı tekniktir. Sorular açık veya kapalı uçlu olabilecek şekilde hazırlanabilir. Uygulanacak ankette sorulan sorular anlaşılır ve kısa tutulmalıdır. Anket uygulaması 3 şekilde de yapılabilmektedir. Bunlar;

- Posta Yoluyla Uygulama

- $\quad$ Yüz yüze Uygulama

- Toplu Halde Uygulama

Anket uygulaması posta yolu ile yapılacak ise, araştırmanın amacı, kim tarafından yapıldığı, sonuçların istenirse geri mail ile dönüş yapılacağı vb. bilgilere yer verilmelidir.

Anket posta yolu ile yapılacak ise; anket uygulanacak kişi gerekli bilgiler verildikten sonra kendisi anket formunu dolduracaktır.

20 | $\mathrm{P}$ a g e

www.iiste.org 
Anket toplu halde uygulanacak ise; katılımcılar bir araya toplanır yada toplu bulundukları yere gidilerek anket uygulaması yapılması ile sonuçlanmaktadır.

İş tatmini ölçülecek anket kişinin çalışma alanında veya var ise bu durumlar için yapılmış yerlerde sağlanmaktadır. Bu tarz anketlerde katılımcı isim yazmak zorunda değildir. Kişisel ölçümden ziyade genel bir iş tatmini ölçümü söz konusudur.

Mülakat ile iş tatmini ölçümünde, karşıllklı konuşma ile iş tatmini/tatminsizliği ölçümü yapılabilmektedir. Yüz yüze yapılması sebebiyle konu aydınlatılması amacıyla farklı sorular sorularak problemlerin daha açık anlaşılması sağlanabilecektir. Bu tarz uygulamalarda mülakat sorularını içeren yol gösterici soruların olması işlemi daha kolay yapılmasında önemlidir. Mülakatta biligiyi direk birinci şahıstan öğrenilmesi sebebiyle bilgi doğruluk derecesi ve kişisel sorunların önlenmesinde önemlidir.

$\mathrm{Bu}$ araştırma, Muş ilinde faaliyet gösteren gıda işletmelerinde çalışanların iş tatmini/tatminsizliği ve mevcut gıda işleme proses bilgilerinin belirlenmesi amacıyla yapılmıştır.

\section{Materyal Ve Yöntem}

Araştırmamızda öncelikle literatür araştırması yapılarak konu ile ilgili eksikliklerin olduğu ve gıda işletmelerindeki iş tatmininin ölçülmesi konusunda araştırma yapılması sonucuna ulaşılmıştır. Çalışmanın teorik kısmı konuya uygun kaynaklar belirlenerek araşıırmanın teorik kısmı hazırlanmıştır. Araştırmanın daha objektif ve gıda işletmelerindeki iş görenlerin görüşlerinin öğrenilmesi amacıyla gıda sektöründe bulunan işletmelerin personellerine anket uygulaması yapılmıştır. Araştırmanın örneklemini Muş ilindeki gıda işletmelerinde farklı pozisyonlarda çalışmakta olan 30 iş gören oluşturmaktadır. Çalışma yazılı anket yoluyla yapılmış̧ır. Hazırlanan anket formları ilgili gıda işletmelerine bizzat gidilerek dağıtılııştr. Belirli bir süre sonra deneklerden toplanmıştır. Anket formunu Katılım boyutu, Uyum, Zoraki çalışma durumu, Ahlaki bağllık, Yönetim ve Takdir, Çalışma Koşulları, İş doyumu, Gıda üretiminde dikkate alınması gereken hususlar gibi ölçekler oluşturmaktadır. Anket sonuçları, SPSS istatistiksel programı kullanılarak değerlendirilmiş̧ir.

\section{Sonuç Ve Öneriler}

$\mathrm{Bu}$ çalışma Muş ilinde faaliyet gösteren gıda işletmelerinde çalışanların iş tatmini/tatminsizliği ve mevcut gıda işleme proses bilgilerinin belirlenmesi amacıyla yapılmış ve elde edilen sonuçlar aşağıda verilmiştir.

Anketi değerlendirilmeyenler katılımcıların \%28'i, işletmede farklı departmanlarla iş birliği yaptığını beyan edenler $\% 34$ 'i, işletmeyi ailesi gibi görenler $\% 25$ ' $i$, işletmede oryantasyon eğitiminin verilmesini isteyenler \% 40 'i, tek işim olsa bunu seçerim diyenler \%21'i ve işimi zevkle yaptığını beyan edenler \%31'i olduğu belirlenmiştir.

Muş ilindeki yiyecek ve içecek hizmetleri sunmakta olan iş görenlerin iş tatmini/tatminsizliği ve mevcut gıda işleme durumunun öğrenilmesi amacıyla yapılan çalışmada iş tatmini kişisel olarak fark etmekle beraber belirli bir yaşa kadar artmakta daha sonra azalmaya başlamaktadır. Bunun sebepleri arasında genç yaşlarda işe başlamış olan bir işgören ile belirli tecrübe ve bilgi birikimine sahip işgörenin işletmelerden beklentileri farklı olabilmektedir. Gıda işletmesinde görev alan işgörenlerin zamanla eğitim düzeyindeki yükseliş ile maaş artış, statü gibi talepleri olabilmektedir.

Gıda işletmelerin sürdürülebilirliği için iş tatmin/tatminsizlik durumlarının belirli periyotlar ile sağlaması gerekmektedir. İşletmeler sadece maddi açıdan çalışanlarının düşünmemeli manevi yönden de desteklemelidir. Başarılı işler sonucunda çalışanını takdir etmiş olan, belirli dönemlerde personel motivasyonunun yüksek olması için personel geceleri düzenleyen işletmeler rakiplerine kıyaslandığında daha başarılı olacaktır. Tüm bu bilgilerin sonucunda aşağıdaki önerilere ulaşılabilir.

1. İşletmelerin belirlenen ve istenilen hedeflere ulaşabilmesi, işletmelerin ayakta kalması, rakiplerine müşteri memnuniyeti sağlanması noktasında üstünlük sağlamaları çalışanların iş tatmin düzeylerinin yüksek olmasına bağlıdır. İşletmede yapılan işte farklı sebepler ile iş tatmini sağlanmayan personelin işletmeye beklenen fayda sağlaması beklemek yanlş̧ bir beklentidir. Bu sebeple iş görenlerin iş tatmini sağlanması ve iş motivasyonu sürekli yüksek olması gerekmektedir.

2. İşletmelerin özellikle gıda işletmeleri gibi personelin müşteri ile sürekli iletişim içinde olduğu hizmet sektöründe personeli mutlu et, personel de seni mutlu etsin anlayışı bulunmaktadır. Bu anlayış personel

21 I P a g e

www.iiste.org 
beklentilerinin sağlayan işletmelerin çalışanları mutlu, verimli, işletmeye bağlılık hissinde olması sebebiyle ilgilenilecek müşteri ile daha özverili çalışmalar neticesinde müşteri memnuniyeti sağlanacaktır. Buda işletmenin var olmasının sebeplerin başında gelmektedir. Müşteri memnuniyeti ileriki zamanlarda artık oraya bir işletme olarak değil, bir ev olarak düşünmesini ve tercihlerin hep memnun kalınan işletmelere gitme eğiliminde olacaklardır.

3. İşletmelerin kırmızı çizgileri olması gerekmektedir. Şöyle ki bir işletme yeni işe aldığı bir personele avans para istemesi durumunda vermiyor başka bir personele veriyor ise burada güven ve iş tatminsizliği ortaya çıkabilecektir. Bu sebeple işletmede herkese adil bir yaklaşım içerisinde olması gerekmektedir.

4. İş tatmini artırılmasında işletmede iş görenin kendini güvende hissetmesi önemlidir. Gıda işletmelerinde özellikle tehlike iş alanları içerisinde mutfak yer almaktadır. Çalışanların güven hissetmesi için mutfakta gerekli iş kazalarına yönelik önlemler alınmalı, mutfak departmanının havalandırması belirli dönemlerde yenilenmelidir.

5. Hayat görüşleri, aynı düşünce de ve uyum içinde çalışmak insanın iş tatminini artıracaktır. İşletmenin en büyük hamlesi uyumlu arkadaşlardan bir grup oluşturmak ve tatlı rekabetler ile hem çalışanlarını hem de işletmeyi daha iyi noktalara çıkarmak olacaktır.

6. İşletmenin personele sağladığı sigorta primlerini yüksek girilmesi, iş kazalarında sigorta sağlaması, işsizlik sigortası gibi faktörler çalışanın iş verimini artıracak eylemler arasındadır.

\section{Kaynaklar}

1. Giritlioğlu, İ., Karakan, H. İ., \& İpar, M. S. (2016, october). Otel İşletmelerinde Yiyecek-İçecek Departmanı Çalışanlarının İş Tatminine Etki Eden Faktörler Üzerine Yazınsal Bir İnceleme. In congress book, 389-399.

2. Çarıkçı, İ. H. (2000). Çalışanların İş Tatminlerini Etkileyen Kişisel Özellikler Süpermarket Çalışanları Üzerinde Bir Araştırma 5(2), 155-168.

3. Kaya, İ. (2007). Otel İşletmeleri İş Görenlerinin İş Tatminini Etkileyen Faktörler: Geliştirilen Bir İş Tatmin Ölçeği 7(2), 355-372.

4. Özcan, E. D. (2010). Algılanan Örgüt Yapısı İle İş Tatmini Arasındaki İlişkide Kişilik Özelliklerinin Rolü ve Bir Araştırma. Doktora Tezi, Marmara Üniversitesi Sosyal Bilimler Enstitüsü İşletme Anabilim Dalı. İstanbul, 177.

5. Pınar, İ. , Kamaşak, R. , \& Bulutlar, F. (2008). İş Tatmini Oluşturan Boyutların Toplam Tatmin Üzerindeki Etkilerinin Doğrulayıcı Faktör Analizi ile İncelenmesi Üzerine Türk İşletmelerinde Bir Araştırma37(2), 151-166.

6. Ayan, B. (2008, Temmuz ). İşletmelerde Eğitimin Çalışanlar Üzerindeki İş Tatminde Gıda Sektöründe Bir Uygulama. Yüksek Lisans Tezi, Yıldız Teknik Üniversitesi Sosyal Bilimler Enstitüsü İşletme Ana Bilim Dalı. İstanbul, 172.

7. Dinler, C. (2019). İş Tatmini ve Yaşam Tatmini İlişkisi: İş Özellikleri Kuramı Yaklaşımı. Yüksek Lisans Tezi, Adnan Menderes Üniversitesi Sosyal Bilimler Enstitüsü Yiyecek İçecek Ana Bilim Dalı. Aydın, 101.

8. Kösem, E. B. (2015). Kurum Kültürünün Çalışanların İş Tatminine Etkileri: Gıda Sektöründe Bir Araştırma. Yüksek Lisans Tezi, İstanbul Ticaret Üniversitesi Sosyal Bilimler Enstitüsü İşletme Anabilim Dalı. İstanbul, 237. 
9. Karaçar, E. (2019). Otel Çalışanlarının İş Tatmini ve Motivasyon Düzey Değişkenleri Üzerine Bir Araştırma: Sinop Örneği. Sinop Üniversitesi Sosyal Bilimler Dergisi, 3(1), 55-78.

10. Urhan, S. (2014). İş Tatmini ve Örgütsel Bağlılık İlişkisi Bir Alan Araştırması. Yüksek Lisans Tezi, Pamukkale Üniversitesi Sosyal Bilimler Enstitüsü İşletme Anabilim Dalı. Denizli, 139.

11. Ergüney, Ö. (2006). Ücret Tatmininin İş Gören Tatmini ile İlişsisi ve Bir Uygulama. Yüksek Lisans Tezi, İstanbul Üniversitesi Sosyal Bilimler Enstitüsü İşletme Anabilim Dalı. İstanbul, 118.

12. Tor, S. S., \& Esengün, K. (2011). Örgütlerde İş Tatminini Etkileyen Demografik Faktörler ve Verimlilik: Karaman Gıda Sektöründe Bir Uygulama. Karamanoğlu Mehmet Bey Üniversitesi Sosyal ve Ekonomik Araştırmalar Dergisi, 2011(1), 53-63. 